\section{BUDGET HIGHLIGHTS}

How science agencies fared in the budget (US\$ millions).

\begin{tabular}{llll}
\hline Agency & $\mathbf{2 0 1 3}$ actual $^{*}$ & $\mathbf{2 0 1 4}$ actual & $\mathbf{2 0 1 5}$ request \\
\hline National Institutes of Health & 29,001 & 30,003 & $\mathbf{3 0 , 2 0 3}$ \\
\hline Centers for Disease Control and Prevention & 5,503 & 5,882 & 5,474 \\
\hline Food and Drug Administration & 2,386 & $2,640+$ & 2,584 \\
\hline National Science Foundation & 7,105 & 7,142 & 7,255 \\
\hline NASA (science) & 4,782 & 5,151 & 4,972 \\
\hline Department of Energy Office of Science & 4,681 & 5,066 & 5,111 \\
\hline Environmental Protection Agency & 7,918 & 8,200 & 7,890 \\
\hline National Oceanic and Atmospheric Administration & 4,906 & 5,322 & 5,497 \\
\hline US Geological Survey & 1,012 & 1,032 & 1,073 \\
\hline
\end{tabular}

*2013 figures include the roughly 5\% across-the-board cut of the budget sequester. $\$ 79$ million in user fees.

at eventually sending astronauts to Mars. If Congress approves the budget proposal, the agency will select the basic outlines of the mission plan early next year.

Obama's budget request also includes $\$ 15$ million for a spacecraft to Europa, an icy moon of Jupiter. The move is an apparent nod to Congress, which last year inserted $\$ 80$ million into the NASA budget explicitly for Europa, despite the administration's objections. At times, NASA has sounded less than enthusiastic about this moon; Beth Robinson, the agency's chief financial officer, told reporters last week that Europa was a challenging environment and that she did not foresee a mission to the moon launching before the mid-2020s.

Overall, NASA's science budget would drop nearly 3.5\% under the president's proposal, to $\$ 4.97$ billion. The biggest casualty would be the Stratospheric Observatory for Infrared Astronomy, a joint US-German project involving a 2.5-metre airborne telescope. NASA says that if other partners cannot supply most of the plane's operating budget, it will ground the observatory from 1 October (see Nature http:// doi.org/rtk; 2014).

Also facing a cut is high-energy physics research at the Department of Energy (DOE), which would fall by $6.8 \%$ to $\$ 744$ million. That has sparked concerns that the US physics community has been too slow to unite behind a viable research agenda. With unfortunate timing, a DOE advisory panel charged with producing such an agenda is scheduled to release its results two months from now. Under consideration are proposals for a new domestic neutrino experiment and US participation in a linear collider, likely to be destined for Japan, that would build on advances at the Large Hadron Collider in Geneva, Switzerland.

"The White House is certainly sending a signal to the high-energy physics community that it needs to get its act together," says Michael Lubell, director of public affairs for the American Physical Society in College Park, Maryland.

To Andrew Lankford, a physicist at the University of California, Irvine, who leads the DOE's High Energy Physics Advisory Panel, the move is not surprising, given Obama's emphasis on climate and clean-energy research and development at the department - these saw a significant boost in the White House budget proposal. Lankford says that the proposal would make it "a challenge to maintain the vitality of our research community" - but he is confident that his panel's report will be completed in time to influence budget negotiations in Congress. SEE EDITORIALP.139

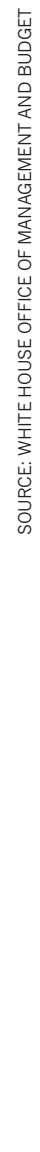

\title{
China goes back to basics on research funding
}

\section{Core science gets budget boost in a bid to change research culture and increase innovation.}

\section{BY JANE QIU}

$\mathrm{L}$ ast week, Chinese science saw some big wins as Premier Li Keqiang delivered his first budget since taking office a year ago. Yet observers have warned that to translate that support into innovation, the country must invest more in basic research and move away from its desire for quick successes.

China's total expenditure on research and development (R\&D) has increased by $23 \%$ a year on average over the past decade. But with uncertainties arising from a new government and the effects of the economic slowdown, scientists had feared cutbacks this year.

At the opening session of the annual National People's Congress in Beijing, however, Li reassured the research community by stressing

\section{CASH DRAW}

In most sectors, China spends more on developing existing technologies than on basic or applied science. The difference is more pronounced than in some other countries.

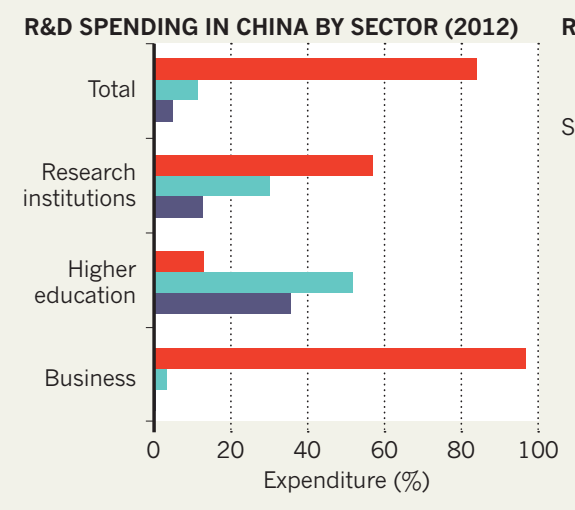

R\&D SPENDING BY COUNTRY

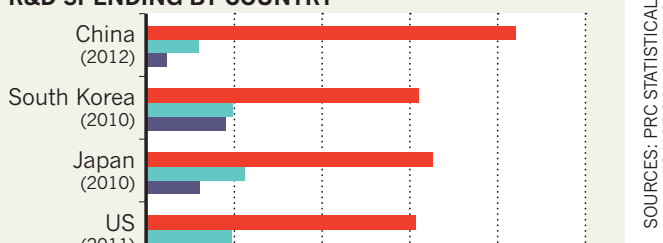

(2011)

(2011) France $\begin{array}{r}(2010) \\ \hline\end{array}$

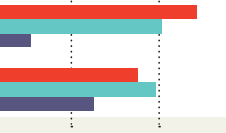

- Development Applied - Basic

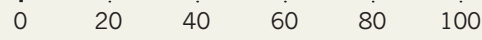

Expenditure (\%) 
5 the importance of scientific innovation to economic growth - and by pledging hard cash.

The central government's expenditure on science and technology this year was set at US $\$ 43.6$ billion (267.4 billion yuan renminbi), an $8.9 \%$ rise on last year, which slightly trails the overall projected budget increase of $9.3 \%$. The biggest winners are 16 'megaprojects' with an emphasis on engineering and applied research in areas such as transgenic crops, nuclear power plants and lunar exploration, which together will receive a whopping $\$ 8.1$ billion.

China's basic-research spending has historically been extremely low - about $4.8 \%$ in 2012 and 2013, compared with 10-25\% in developed nations (see 'Cash draw'). But this year, the appropriation for basic research will increase by $12.5 \%$ to $\$ 6.6$ billion - of which the National Natural Science Foundation of China is slated to get $\$ 3.1$ billion, says its president, Yang Wei. The major areas that the foundation will fund include studies of biodiversity, air pollution, supercomputers, neurodegenerative diseases and scientific equipment.

Two of the 16 megaprojects have a substantial basic-research component: these are in the areas of drug discovery and major infectious diseases, including HIV/AIDS and influenza. And with a combined budget of $\$ 488$ million, the two initiatives "will continue to strengthen the capacity for drug screening, rapid detection of pathogens and vaccine development", says Liu Qian, deputy director of the National Health and Family Planning Commission, who oversees the projects.

The Ministry of Science and Technology will spend about $8 \%$ of its total budget of $\$ 8.1$ billion on basic research — including \$211 million on six major science programmes in areas such as nanotechnology, quantum physics, stem cells and protein science - and $\$ 1.1$ billion on developing key technologies.

The Chinese Academy of Sciences (CAS), which relies mostly on extramural grants to fuel its research, will receive $\$ 423$ million for 20 'strategic priority projects' in areas ranging from neuroscience to studies of the Tibetan Plateau.

Although such strong support is welcomed, observers such as Richard Suttmeier, a policy researcher at the University of Oregon in Eugene who advises China's science ministry, fear that more money may not bring more innovation without a sea change in how it is spent, and without a shift in China's research culture

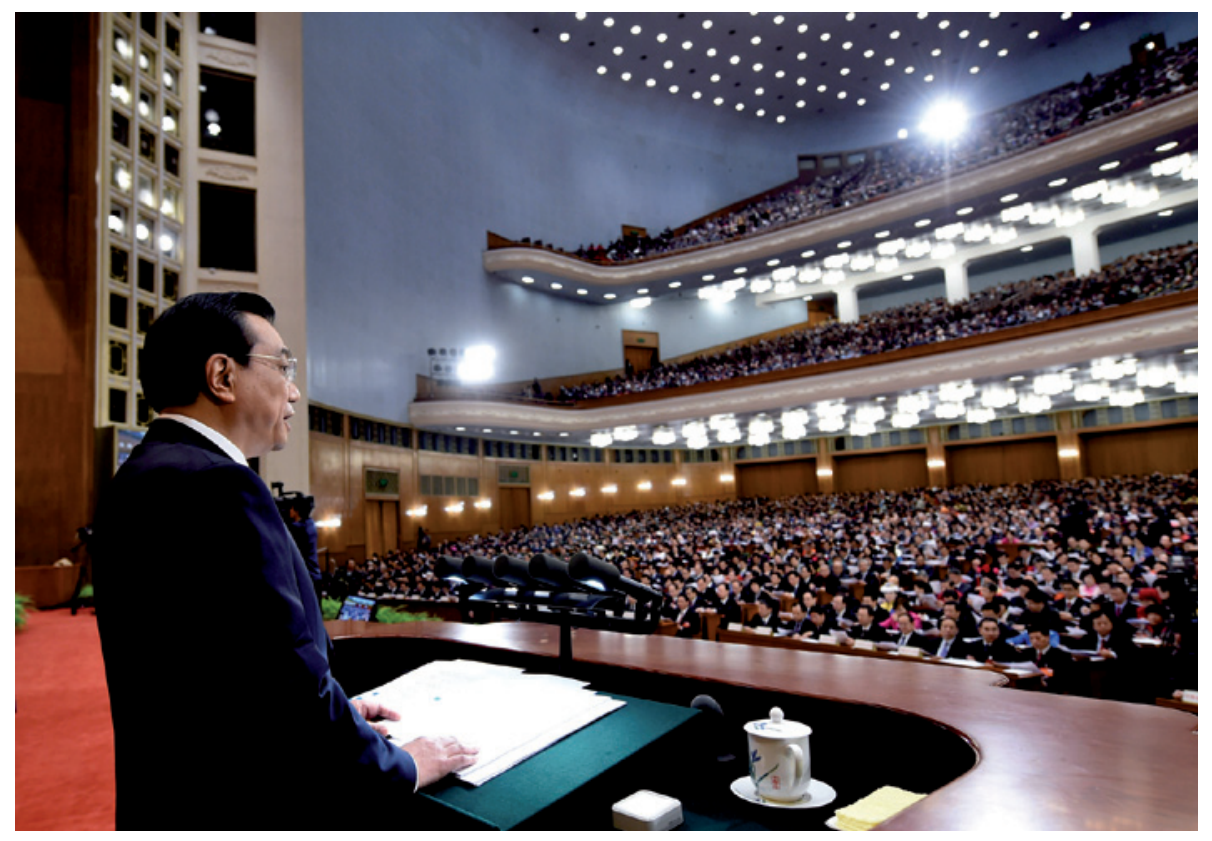

Premier Li Keqiang pledged support for basic science at last week's National People's Congress in Beijing.

and institutions. This is because of serious concerns about the country's quality of research.

"While China's output of publications and patents is impressive, there are very few genuine innovations," says CAS president Bai Chunli. A key reason, says Yang, is the modest government support for basic research. Moreover, he adds, "a large chunk of China's R\&D expenditure comes from industry”. In 2012, industry contributed $76 \%$ of all R\&D funding but spent almost nothing on basic science and only $3 \%$ on applied research, he says (see 'Cash draw'). Consequently, $84 \%$ of China's total R\&D spending goes on product development, such as the commercialization of technologies, compared with $35-65 \%$ in developed economies.

Even research institutes spend only $13 \%$ of their funding on basic science and less than one-third on applied research, and are under increasing pressure to engage in development projects that focus on real-world problems. Without a firm footing in solid research, such projects "have limited value in developing an innovative economy", says Su Jun, a policy researcher at Tsinghua University in Beijing.

Chinese scientists are also concerned by the serious misuse of research grants. A report released by China's National Audit Office last October shows that the problem is widespread
- and that up to half of all research funding has been misused. In a crackdown, one vicepresident of Zhejiang University was arrested last December on "suspicion of occupational crime", according to the Xinhua news agency, and 50 officials at the Guangdong Provincial Department of Science and Technology are under investigation for embezzling R\&D funds.

When research grants are used as intended, Chinese science "suffers from excessive bureaucratic interference and a culture of jigong jinli - seeking quick success and short-term gain", says Muming Poo, director of the CAS Institute of Neuroscience in Shanghai. Officials often demand the demonstration of productivity on an almost yearly basis, and grants can be slashed by $50 \%$ if researchers fail in this task.

"The Chinese government is aware of the problems and institutional reforms are firmly on the agenda of the congress to boost $\mathrm{R} \& \mathrm{D}$ efficiency," says Bai. Topics under discussion at the congress included increasing the proportion of basic research in total R\&D to $10 \%$ by 2020 ; instigating policies to encourage investment in basic and applied research; reforming funding and evaluation systems; raising the budget for research overheads; and giving scientists more freedom. Such changes "will be crucial for Chinese science to reach the next level”, says Bai. -

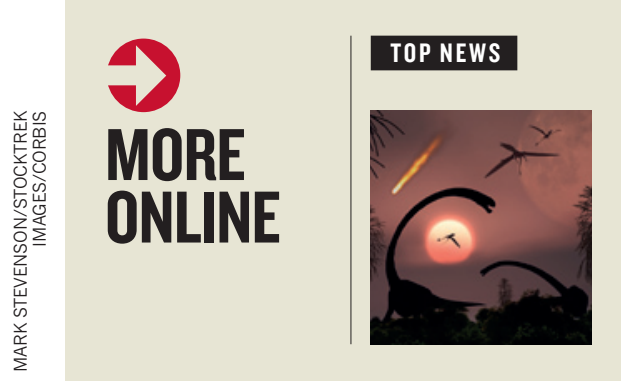

Sun's passages A potential blood test for early through Alzheimer's detection go.nature.com/ dark-matter nmaime disk could trigger periodic extinctions go.nature.com/x6fx77

- Beautiful maths is like art to the brain go.nature.com/rtjypj

- River-basin geometry slowly shifts before it settles go.nature.com/5ytp2y

\section{NATURE PODCAST}

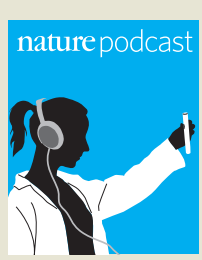

A medieval multiverse theory; a rare mineral from Earth's mantle; and wolves in Yellowstone nature. com/nature/podcast 